\title{
From Jigsaw Pieces to Full Picture
}

All indicators signal growth for lightweight design. A position paper from the leading German industry and research associations in the field of lightweight design published in July emphasises the significant relevance of the topic for the economy. Also a study published by management consultants Mc Kinsey estimates annual sales of components made from high-strength steel, aluminium and CFRP are set to increase more than fourfold from 2010 's figure of 70 billion euros to more than 300 billion euros by 2030 in the automotive industry alone.

These assessments are only too plausible - after all, we live in a world wishing to eliminate fossil fuels while adequate alternative sources of energy and ways of storing it are not available to cover the increasing needs of mobility. Lightweight design on its own will not solve these problems, but it can make an important contribution towards the more efficient use of our scarce resources.

Nevertheless, the optimistic forecasts must not be allowed to disguise the current situation in lightweight design. While impressive products and technologies are indeed available to us - hybrid materials, multi-material vehicle bodies, modern aircraft with significantly reduced weight we can nevertheless see that, with the specialist knowledge that we have built up in many places, we face what seems like an unfinished jigsaw puzzle whose individual parts still do not form a complete picture. Numerous research institutes have developed innovative technologies, but there is a problem when it comes to industrial exploitation. Individual players from the research and business fields must collaborate more than they have done in the past in order to capitalise on existing knowledge.

And there is still more work waiting. According to an estimate from public development agency Leichtbau BW, a maximum of $30 \%$ of the total possible reduction in the mass of moving structures can be achieved following the approach to material lightweight design that we generally take today. Function integration and load-specific construction or, in short, system lightweight design, are the key to fully weight-optimised structures.

We are only just at the beginning of this process and, quite logically, the focus is turning to one specific topic: the digital networking of all processes from product development and quality assurance to recycling. For example, an engineer wishing to use a composite material already needs to have some idea of the economics of large-scale production during the planning stage. At the same time, he needs to be certain that his development will meet all crash safety requirements.

It is only when the consequences of the design details for the later stages of a product's life are clear that the full potential of the lightweight design of a structure can be realised. Or expressed metaphorically, the lightweight design jigsaw forms a complete picture. 